\title{
LESÃO RENAL AGUDA NO ACIDENTE APÍLICO
}

\section{Sabrina Karen Medino Malveira ${ }^{1}$; Naiane Nadylla Nobre Sombra ${ }^{2}$; Isabelly Crysthynne Moreira da Luz ${ }^{3}$; Ricardo Serejo Tavares ${ }^{4}$; Sandra Mara Brasileiro Mota ${ }^{5}$; Geysa Aguiar Romeu $^{6}$}

' Acadêmica de Medicina, Centro Universitário Christus (UNICHRISTUS), Fortaleza, Ceará. 2Acadêmica de Farmácia, Centro Universitário Maurício de Nassau (UNINASSAU), Fortaleza, Ceará.

${ }^{3}$ Acadêmica de Farmácia, Universidade Federal do Ceará (UFC), Fortaleza, Ceará.

${ }^{4}$ Acadêmico de Medicina, Universidade de Fortaleza (UNIFOR), Fortaleza, Ceará.

${ }^{5}$ Farmacêutica Bioquímica, Centro de Informação e Assistência Toxicológica do Instituto Dr. José Frota (CIATox/IJF), Fortaleza, Ceará.

'Farmacêutica, Centro de Informação e Assistência Toxicológica do Instituto Dr. José Frota (CIATox/IJF), Fortaleza, Ceará. sabrinakmm@hotmail.com

DOI: $10.47094 /$ ICONNACT.2020/110-112

\section{RESUMO}

INTRODUÇÃO. A abelha brasileira, popularmente conhecida como abelha de mel ou abelha africanizada, apresenta comportamento defensivo, com ataques em massa; sua picada pode ocasionar desde efeitos locais a sistêmicos graves, em casos raros, o paciente pode evoluir com síndrome de envenenamento, caracterizada principalmente por alteração da função renal. OBJETIVO. Avaliar um caso grave de acidente apílico. METODOLOGIA. Relatar o caso de um paciente, vítima de acidente aṕlico, por meio da análise de prontuário presente na base de dados de um centro de informação e toxicologia do Ceará. RESULTADOS E DISCUSSÕES. Paciente, 75 anos, vítima de múltiplas picadas de abelha apresentou hemólise, rabdomiólise, e lesão renal aguda. Após procedimentos específicos e várias sessões de hemodiálise, evoluiu com melhora da lesão renal, recebendo alta hospitalar. CONCLUSÃO. O caso apresentado reitera a importância do diagnóstico e intervenções precoces nos acidentes apílicos, além de demonstrar a relevância da hemodiálise na resolução dos quadros graves.

PALAVRAS-CHAVE: Abelhas; Intoxicação; Rabdomiólise.

ÁREA TEMÁTICA: Assistência e Atenção diagnóstica 


\section{INTRODUÇÃO}

As abelhas brasileiras são resultados de uma hibridização acidental entre abelhas africanas trazidas da África (Apis mellifera scutellata), com as européias (Apis mellifera lingustica) existentes na natureza brasileira. Com características agressivas e ataques violentos em massa, podem causar reações sistêmicas graves e até mesmo fatais (1). A Lesão Renal Aguda (LRA) é uma condição patológica que pode ocorrer após ataques maciços de abelhas, e isso se deve a vários fatores como hemólise intravascular, rabdomiólise, hipotensão e toxicidade direta dos componentes do veneno para os túbulos renais (2). A rabdomiólise é uma síndrome caracterizada por lesão muscular extensa causada por trauma muscular, imobilização prolongada, estado de mal convulsivo, hipertermia maligna, exercício físico extenuante, exposição as drogas e ataques de abelhas africanizadas (3). Descrevemos um caso de acidente por picada de abelhas africanizadas que evoluiu para LRA grave e dialítica, secundária à rabdomiólise.

\section{MATERIAL E MÉTODOS}

Análise retrospectiva do prontuário de um paciente admitido no Instituto Dr José Frota em Fortaleza (Ceará), em agosto de 2020, vítima de acidente apílico com múltiplas picadas que progrediu com rabdomiólise e LRA grave. A equação CKD-EPI foi utilizada para o cálculo da taxa de filtração glomerular estimada (eTFG).

\section{RESULTADOS E DISCUSSÃO}

L.M.S., 75 anos, masculino, agricultor familiar, hipertenso e com história prévia de neoplasia de próstata em interrupção de tratamento há 1 ano, vítima de acidente apílico de múltiplas picadas com lesões distribuídas em toda a extensão corporal. O tempo decorrido entre o acidente e o atendimento em serviço de urgência foi de 6 horas. As características laboratoriais na admissão revelaram aumento da uréia (Ur = 84 U/L; VR: 15-39) e creatinina sérica $(\mathrm{Cr}=3,6 \mathrm{mg} / \mathrm{dL}$; VR: 0,8-1,3), diminuição da taxa de filtração glomerular ( $\mathrm{eTFG}=18,06 \mathrm{~mL} / \mathrm{min} / 1,73$; VR $>90 \mathrm{~mL} / \mathrm{min} / 1,73$ ), alargamento dos testes de coagulação (INR=1,39), e elevação da creatina fosfoquinase (CPK=33.886 U/L; VR: 39-308 ). Ao exame físico, apresentava-se com presença de edema facial, sonolento, taquicárdico, oligúrico com presença de pigmentos de mioglobina na urina, Sinais vitais: Pressão Arterial $=144 \mathrm{x}$ $97 \mathrm{mmHg}$; Frequência Cardíaca $=100 \mathrm{bpm}$; Saturação de Oxigênio $=97 \%$; Temperatura $=36,1{ }^{\circ} \mathrm{C}$. Evoluindo com LRA grave $(\mathrm{Cr}=6,1 \mathrm{mg} / \mathrm{dL}$; VR: 0,8-1,3; eTFG =9,54 mL / $\mathrm{min} / 1,73$; VR $>90 \mathrm{~mL}$ $/ \min / 1,73)$. 
No $8^{\circ}$ DIH (Dia de Internamento Hospitalar) paciente apresentou anemia (hemácias 2,4 milhões $/ \mathrm{mm}^{3}$; hemoglobina $6,8 \mathrm{~g} / \mathrm{dL}$; hematócrito 19\%). Neste momento, solicitou-se parecer do hematologista e o mesmo prescreveu infusão de dois concentrados de hemácias, previamente à hemodiálise. Durante o internamento, realizou, no total, 16 sessões de hemodiálise e hidratação rigorosa, evoluindo com melhora do edema e parâmetros laboratoriais. Recebeu alta hospitalar no $43^{\circ}$ DIH apresentando aumento progressivo do débito urinário e com os seguintes resultados de exames: Hemoglobina: 7,8 g/dL; Leucócitos: 6150 mm³; Plaquetas: 343.000 mm³; Ur: $66 \mathrm{U} / \mathrm{L}$; Cr: 2,7 mg/dL; Proteína C Reativa: 62,9 mg/L, sendo o tratamento dialítico suspenso e encaminhado para acompanhamento ambulatorial.

\section{CONCLUSÃO}

LRA induzida por rabdomiólise no acidente apílico é uma manifestação grave que pode ser fatal, e o tratamento precoce e de forma agressiva desta síndrome, se faz necessário à completa recuperação do paciente. Conclui-se também que a hemodiálise é um método de terapia de substituição renal que se mostrou eficaz na depuração de toxinas e seus produtos no acidente por abelhas africanas, diminuindo assim o risco de morte nestes pacientes.

\section{PRINCIPAIS REFERÊNCIAS:}

1. SILVA, Geraldo Bezerra da Junior. et al. "Acute kidney injury complicating bee stings - a review.”. Rev Inst Med Trop São Paulo, v. 59, e 25, Jun. 2017.

2. DAHER, Elizabeth De Francesco. et al . Acute renal failure after massive honeybee stings. Rev. Inst. Med. trop. S. Paulo, São Paulo , v. 45, n. 1, p. 45-50, Jan. 2003 . Available from <http:// www.scielo.br/scielo.php?script=sci_arttext\&pid=S0036-46652003000100010\&lng=en\&nrm=iso $>$. access on 26 Nov. 2020.

3. DAHER, Elizabeth De Francesco. et al . Insuficiência renal aguda por picada de abelhas: relato de casos. Rev. Soc. Bras. Med. Trop., Uberaba , v. 42, n. 2, p. 209-212, Apr. 2009 . Available from $<$ http://www.scielo.br/scielo.php?script=sci_arttext\&pid=S0037-86822009000200024\&lng=en\&nr $\mathrm{m}=\mathrm{iso}>$. access on 26 Nov. 2020. 